\title{
A Review of the most popular Language learning strategies' evaluation instruments
}

\author{
Shohreh Raftari, Saber Alawi \\ School of Languages, Literacies and Translation, University Sains Malaysia
}

\begin{abstract}
There are some different ways to evaluate language learning strategy [LLS] use. The present article is a review of three most widely used data collection instruments in the field of language learning strategies i.e. self-report inventories, interviews and think aloud protocol.
\end{abstract}

Keywords: language learning strategy, evaluation instrument, inventory, interview, think aloud protocol

\section{Introduction}

Oxford and Burry-Stock (1995) classify the LLS's evaluation methods into seven categories of questionnaire, observation, interview, group discussion, diaries and dialogue journals, re-collective narratives and think aloud protocols. These methods and their advantage and disadvantages are profiled in figure 1.

Figure 1: Classification of LLS's evaluation methods (Oxford \& Burry-Stock, 1995)

\begin{tabular}{|c|c|c|}
\hline $\begin{array}{l}\text { Strategy Assessment } \\
\text { Techniques }\end{array}$ & Advantages & Disadvantages \\
\hline 1. Questionnaires & $\begin{array}{l}\text { Easy \& quick } \\
\text { Cost effective } \\
\text { Providing a general assessment of each student's } \\
\text { typical strategies across a variety of possible tasks } \\
\text { Unthreatening to confidentiality }\end{array}$ & $\begin{array}{l}\text { Doesn't describe in detail the LLSs a } \\
\text { student uses in response to any } \\
\text { specific language task }\end{array}$ \\
\hline 2. $\quad$ Observation & Easy to use especially in class & $\begin{array}{l}\text { Can't provide info on unobservable } \\
\text { mental strategies such as reasoning } \\
\text { or analyzing }\end{array}$ \\
\hline 3. Interview & $\begin{array}{l}\text { Whether formal/informal provides personalized } \\
\text { info on many types of strategies }\end{array}$ & Time-consuming \\
\hline 4. Group discussion & $\begin{array}{l}\text { Can give a wonderful picture of the strategies used } \\
\text { by the whole class }\end{array}$ & $\begin{array}{l}\text { Doesn't give individualistic strategy } \\
\text { use of specific students }\end{array}$ \\
\hline $\begin{array}{l}\text { 5. Diaries \& dialogue } \\
\text { journals }\end{array}$ & $\begin{array}{l}\text { Provide detailed rich data on learning strategies for } \\
\text { individuals }\end{array}$ & $\begin{array}{l}\text { Don't provide direct comparisons } \\
\text { between students because of their } \\
\text { open-ended nature }\end{array}$ \\
\hline $\begin{array}{l}\text { 6. Re-collective } \\
\text { narratives }\end{array}$ & $\begin{array}{l}\text { Provide a big picture of the whole learning process } \\
\text { uniting LLSs with other important aspects of } \\
\text { learning such as motivation and learning style }\end{array}$ & $\begin{array}{l}\text { Might be influenced by slight loss of } \\
\text { details }\end{array}$ \\
\hline $\begin{array}{l}\text { 7. } \begin{array}{l}\text { Think-aloud } \\
\text { protocols }\end{array} \\
\text { prots }\end{array}$ & Provide the most detailed information & $\begin{array}{l}\text { Very time-consuming } \\
\text { Reflect the strategies related just to } \\
\text { the task at hand } \\
\text { Are not summative }\end{array}$ \\
\hline
\end{tabular}

II. The Development Of The Strategy Use Evaluation Instruments

Although all the aforementioned methods can be used to collect data about the students' use of strategies, reviewing the literature in the field of language learning strategies, clarifies that the three data collection instruments of inventories, interview and think aloud are of the most popularity and foremost use. In this section these three instruments are thoroughly discussed.

\section{Questionnaires Or Summative Inventories}

One of the most popular ways to assess the use of LLSs is using a questionnaire. In almost all the strategy assessment studies worldwide some type of questionnaire is utilized and usually one or two of the other methods are used with a smaller fraction of the sample participants to increase the validity of the study data. To discuss some different strategy inventories, this study starts with Bialystok (1981), who according to Oxford and Burry-Stock (1995) designed one of the first student-completed summative language learning strategy scales. Bialystok (1981) designed a 12-item structured, untitled rating scale to assess strategy use. The 12 items were statements according to which the participants were to choose a choice on a 4-point Likert-scale indicating "often," "sometimes," "rarely," and "never." These categories were assigned values of 3, 2, 1, and 0 respectively. 
Thus higher scores indicated greater use of the strategies. The questionnaire examined the language learners' use of four strategies by asking them to indicate the extent to which they engaged in a variety of activities. It asked questions about the extent to which strategies were used on both oral and written tasks in communicative settings [which were the two strategies of functional practice and Inferencing/guessing] also in formal classroom settings [which were the two strategies of formal practice and monitoring] accordingly on the whole measuring the test takers' use of only four strategies. These activities represented instances of using each of the strategies in each modality [oral/written], and for each of reading, writing, listening, and speaking skills. Using her scale with 157 students of French as an L2 in Canada, she found that functional practice had a stronger relationship with achievement than did any of the other strategies, even though monitoring and inferencing were used more often. She did not examine the reliability and validity of her device.

The next known questionnaire in this field was designed by Politzer (1983). It was a 4-scaled strategy questionnaire with 51 items including 3 groups of general behaviours, classroom behaviours and interactions outside class. Without testing the device's reliability and validity, he surveyed the US university students studying French, German and Spanish as foreign languages and found a positive significant correlation between the student's proficiency and their use of reinforcing strategies i.e. strategies related to communicative language proficiency. He also realized that females used more social learning strategies than men.

Once more Politzer in a cooperative study with McGroarty in 1985 designed a 3 part 60 item LLSs use examination questionnaire according to the survey of the available literature on the behaviours and strategies of good language learners [mainly (Naiman, Frohlich, Stern, \& Todesco, 1978; Rubin, 1981)]. The reported reliability for the questionnaire's 3 sections i.e. individual study behaviours, classroom behaviours and interactions outside the class were marginally acceptable [.51, .61 and .63]. They surveyed 37 Asian and Hispanic intensive ESL students in an eight week intensive course. The results revealed that the major academic field had a significant effect on strategy choice. The engineering students generally avoided positive strategies in the field of communicative language proficiency improvement. He also reported an overlap of nationality, since the engineers were generally Asian.

Chamot et al., (1987) designed a 48-item, 4-scaled Learning Strategy Inventory which was composed of five sections: listening in class, speaking in class, listening and speaking outside class, writing and reading. The items in this instrument documented different applications of 16 various strategies. The designers of this inventory did not publish any information related to its reliability and validity. They conducted a study using their instrument over 67 high school students of Spanish and 34 college students of Russian, and increased their data validity through interviewing a sample of the participants. Results indicated that students used a wide variety of strategies regardless of the language under study, and that the students, regardless of their proficiency levels, used predominantly cognitive strategies supported by metacognitive strategies that helped them plan, monitor and evaluate their work, a result in total contradiction with the already discussed studies in the field that reported an increase of strategy use as a result of the increase in students' proficiency.

After discussing some unpopular but pioneering strategy inventories it is now the time to turn to the most famous and popular language learning strategy questionnaire which after more than two decades of its publication is still in use in almost all the studies in the field, Strategy Inventory for Language Learning [SILL] (Oxford, 1986-present).

As it was viewed, few of the previous LLS devices had any published reliability or validity information and according to Oxford and Burry-Stock (1995) this was the key reason at the back of SILL's designation.

SILL was first designed as an instrument to assess the frequency of language learning strategy use by the students at the Defence Language Institute in Monterey, California. It was later revised and two versions of it were published, one for the native English speakers who are learning other languages as their FL/L2 which consisted of 80 items, and the other for EFL/ESL learners with 50 items which are elaborately published in Oxford (1990)'s book, 'Language learning strategies: what every teacher should know'.

The SILL uses a choice of five Likert-scale responses for each statement or strategy described: always/almost always true of me, generally true of me, somewhat true of me, generally not true of me and never/almost never true of me. The responses are based on the Learning and Study Strategies Inventory described by Weinstein et al. (1987) which is widely used and very well accepted.

In 1989, through factor analysis, SILL was sub scaled into 6 groups as follows (Oxford \& Burry-Stock, 1995):

1. Memory strategies, such as grouping, imagery, rhyming and structured reviewing [9 items]

2. Cognitive strategies, such as reasoning, analysing, summarizing -all reflective of deep processing- as well as general practicing [14 items]

3. Compensation strategies, such as guessing the meanings from the context in reading and listening and using synonyms and gestures to convey meaning when the precise expression is not known [six items].

4. Metacognitive strategies, such as paying attention, consciously searching for practice opportunities, planning for language tasks, self-evaluating one's progress and monitoring errors [nine items] 
5. Affective/emotional/motivation-related strategies, such as anxiety reduction, self-encouragement and self-reward [six items]

6. Social strategies, such as asking questions, cooperating with the native speakers of the language and becoming culturally aware [six items].

Any SILL package is made up of: a short set of directions to the student with a sample item, the instrument itself [either the 50/80 item inventory], a scoring worksheet on which the student records her answers and calculates her average for each strategy subscale and their overall average, a summary profile that shows student's result and provides examples for student self-interpretation, and a strategy graph that allows each learner to graph results from the SILL. A background questionnaire is also available to document age, gender, language experience, motivation and other information (Oxford \& Burry-Stock, 1995).

\section{Interview}

According to Platt (2001), there is no history conceivable for interview. She argues that interview has always existed and has only undergone different changes in the course of time. It has in the past been regarded as part of other broader data collection methods such as 'surveys' or 'case studies' and later been distinguished and theorized as a distinct information acquisition discipline.

Gall et al. (2007) define interview as a data collection instrument in both qualitative and quantitative research in which one or more people are questioned orally by one or more people. The interviewer/s must not distract the respondent/s by taking notes. They have to either video/tape record the interview or keep the provided responses in their memory for later recall and note making after the interview.

Cohen and Manion (1994) introduce six reasons for conducting interview in social sciences:

- As a means of evaluating or assessing a person in some respect

- For selecting or promoting an employee

- For effecting therapeutic change, as in the psychiatric interview

- For testing or developing hypothesis

- For gathering data, as in surveys or experimental situations, and finally

- For sampling respondents' opinions, as in doorstep interviews.

They further discuss different types of interview under the distinct category of a tool for gathering data in research which is itself subdivided into four types:

$>$ Totally formal interview, in which set questions are asked and the answers are recorded on a standardized schedule

$>$ Less formal interview, in which the interviewer is free to modify the sequence of questions, change the wording, explain them, shorten them or even add to hem

$>$ Totally informal interview, in which the interviewer may have a number of key issues which she raises in conversational style instead of having any set questionnaire and finally

$>$ The non-directive interview, where the interviewer follows whatever issue which is raised and in fact takes a subordinate role.

According to L. Cohen and Manion (1994) interview can be used as a data collection instrument in three ways:

- As the principal data gathering instrument which directly affects theresearcher's onbjectives

- As a device to test hypothesies or suggest new ones; or as an exploratory device to help identify variables and relationships and finally

- As a conjunction with other methods to further validate other instrument/s' results.

Mackay and Gass (2005) refer to the advantages of interview as:

- Allow researchers to investigate phenomena that are not directly observable, such as learner's selfreported perceptions or attitudes in educational research

- Are interactive, as a result provide the situation for researchers to elicit additional information if the initial answers are vague, incomplete, off-topic, or not specific enough

- Can be used to elicit data from learners who are not comfortable with other data collection instruments, for example those who feel more relaxed talking than writing

- Specifically in L2/FL research, the interview can be conducted in the interviewee's first language impacting the collected data positively both from quantitative and qualitative points of view.

\section{Think Aloud Protocol}

The study of the correlation between thought and language is one of the areas of both psychology and education. In these areas a clear understanding of relations between thought and language is of tremendous importance; though, deciding over this relationship is very difficult. This difficulty stems from the impossibility of direct study of the existing interrelationship.

Psychological linguists define thought as 'speech minus sound' (Vygotsky, 1986), and think aloud is the procedure that combines thought and speech or in the other words turns thought in to language. As an 
example in educational studies, think aloud, in the area of reading strategy speculation, is conducted to realize what is happening in a reader's mind while reading a passage.

The think aloud method is rooted in psychological studies and was developed from introspection method. In introspection an experienced psychologist observes the actions and action products of a person and interprets them to reach to the case's consciousness events. After a period of time the same psychologists, who used introspection, questioned its reliability. The solution suggested to the raised problems was a simpler method in which instead of someone else observing and interpreting a person's actions, the person himself reported of what was happening in his mind while doing a special activity (Someren, Barnard, \& Sandberg, 1994). In the course of its history, verbal report has been used in different areas of science and for different uses. At the beginning, it still was part of introspective studies [Titchener, 1912], in studies on problem solving analysis by Gestalt psychologists [Duncker, 1945; Selz, 1913, 1922; Wertheimer, 1945], clinical thought analysis [Freud, 1914] and finally synthesis of children's thought development [Inhelder\& Piaget, 1958]; however the most recent focus of think aloud use in research has been in problem solving studies within an information processing framework [Newell, Shaw \& Simon, 1958; Newell \& Simon, 1972] (Ericsson \& Simon, 1987).

Think aloud is introduced as a valid method of data gathering in education which sheds light on the cognitive processes happening in the subject's mind through studying and interpreting his reports of his thoughts. In this method, the subject is asked to perform a task and while performing the task talk of the happenings in his mind, such as the strategies a foreign language learner uses to guess the meaning of an unknown word while reading a foreign text. Whatever the subject says and does is video/tape recorded; also, the researcher may take notes of the subject's actions. The recorded data will later be transcribed, synthesised and interpreted by a specialist (Hild, 2007).

To give a better description, verbal protocols are oral records of subjects' thoughts, while thinking aloud during [introspective] or immediately after [retrospective] completing a task. These reports represent the currently available short term memory information and not the real information productive cognitive processes. The desired cognitive processes have to be inferred by the researcher. To code and later interpret the reports the researcher either has to use and adopt an existing coding scheme [e.g. (Mokhtari \& Sheorey, 2002)'s classification of foreign language reading strategies] or design a scheme of his own. However, for the latter option he ought to carefully examine and synthesise the available coding schemes [e.g. (Mokhtari \& Richard, 2002; Mokhtari \& Sheorey, 2002; Oxford, 1986-present) in the field of reading strategy research] to check on their suitability to the study at hand. After reviewing all the present schemes, they are all found incompatible with the researcher's theoretical perspective and the research questions, the researcher will be obliged to develop a new coding system to suit his study (Kasper, 1998).

\section{Conclusion}

The present paper is a brief review of the most popular devices used in the study of learning strategies. The different characteristics of inventories think aloud protocol and interviews are presented. The paper doesn't compare the instruments because these are the instruments which are generally used interchangeably by different researchers in the field.They are even sometime used together in the same study to fulfil the triangulation aim. Any of the discussed instruments has got its own pros and cons; however, what is certainly clear from the review of the related literature, these three instruments are the most beneficial reasonable ones which are the most popular of the different data collection instrument and methods in the field of learning strategy research.

\section{References}

[1] Bialystok, E. (1981). The role of conscious strategies in second language proficiency. Modern Language Journal, 65, 24-35.

[2] Chamot, A. U., O’Malley, J. M., Kupper, L., \& Impink-Hernandez, M. (1987). A Study of Learning Strategies in Foreign Language Instruction. First Year Report (O. o. I. E. (ED), Trans.) (pp. 138). Washington, DC.: Interstate Research Associates, Inc., Rosslyn, VA.

[3] Cohen, L., \& Manion, L. (1994). Research methods in education (4th ed.). Britain: Routledge.

[4] Ericsson, K. A., \& Simon, H. A. (1987). Verbal Reports on Thinking. In C. Farech \& G. Kasper (Eds.), Introspection in Second Language Research. Clevdon. Philadeldelphia: Multilingual Matters LTD.

[5] Gall, M. D., Gall, J. P., \& Borg, W. R. (2007). Educational Research: An introduction. U.S.A.: Allyn and Bacon.

[6] Hild, G. (2007). Investigating a Hungarian language learning aptitude test with think-aloud protocol. In J. Horváth \& M. Nikolov (Eds.), Empirical studies in English applied linguistics (pp. 255-268). Pécs: Lingua Franca Csoport.

[7] Kasper, G. (1998). Analysing Verbal Protocols. TESOL Quarterly, 32(2), 358-362.

[8] Mackay, A., \& Gass, S. M. (2005). Second Language Research: Methodology and Design. Mahwah, New Jersey: Lawrence Erlbaum Associaes, Inc., Publishers.

[9] Mokhtari, K., \& Richard, C. A. (2002). Assessing students' metacognitive awareness of reading strategies. Journal of educational psychology, 94, 249-259.

[10] Mokhtari, K., \& Sheorey, R. (2002). Measuring ESL students' awareness of reading strategies. Journal of Developmental Education, 25(3), 2-10

[11] Naiman, N., Frohlich, M., Stern, H., \& Todesco, A. (1978). The Good Language Learner Toronto: OISE. 
[12] Oxford, R. L. (1986-present). Strategy Inventory for Language Learning. Various versions. : Tuscaloosa, AL: Oxford Associates.

[13] Oxford, R. L. (1990). Language learning strategies: what every teacher should know: Newbury House Publisher.

[14] Oxford, R. L., \& Burry-Stock, J. A. (1995). Assessing the use of language learning strategies worldwide with the ESL/EFL version of the strategy inventory for language learning (SILL). System, 23(1), 1-23.

[15] Platt, J. (2001). The History of the Interview. In J. F. Gubrium \& J. A. Holstein (Eds.), Handbook of Interview Research. U.S.A.: Sage Publications Ltd.

[16] Politzer, R. L. (1983). An exploratory study of self-reported language learning behaviors and their relation to achievement. Studies in Second Language Acquisition, 6, 54-63.

[17] Rubin, J. (1981). Study of cognitive processes in second language learning. Applied Linguistics, 11, 117-131.

[18] Someren, M. W. v., Barnard, Y. F., \& Sandberg, J. A. C. (1994). THE THINK ALOUD METHOD: A practical guide to modelling cognitive processes. London: Academic Press.

[19] Vygotsky, L. S. (1986). Thought and Language (revised edition). Massachusett: The Massachusett Institute of Technology (MIT) Press.

[20] Weinstein, C. E., Palmer, D., \& Schulte, A. C. (1987). Learning and Study Strategies Inventory, Clearwater, Florida: H \& H Publishers. 